\title{
On the dynamic interaction effects of railway tunnels: \\ Crossrail and the Grand Central Recording Studios
}

Journal Title

$X X(X): 2-30$

(C) The Author(s) 2015

Reprints and permission:

sagepub.co.uk/journalsPermissions.nav

DOI: $10.1177 /$ ToBeAssigned

www.sagepub.com/

@SAGE

Daniel Brookes ${ }^{1}$, Waleed I Hamad ${ }^{1}$, James P Talbot $^{1}$, Hugh E M Hunt ${ }^{1}$ and Mohammed F M Hussein² 


\begin{abstract}
In cities around the World, underground railways offer an environmentally-friendly solution to society's increasing demand for mass transport. However, they are often constructed close to sensitive buildings, where the resulting ground-borne noise and vibration can cause disturbance to both occupants and equipment. Such a scenario occurred in central London, where the new twin-tunnels of Crossrail were bored beneath the Grand Central Recording Studios, causing an immediate concern. As a result, vibration in the studios building was monitored throughout the Crossrail construction period. Since Crossrail is yet to operate, the resulting data provides a unique opportunity to investigate the effect of new tunnels, acting as passive buried structures, on the existing vibration environment. This paper presents the results of such an investigation, together with complementary results from a theoretical four-tunnel boundary-element model. The data analysis, presented in the first half of the paper, indicates that the construction of the second Crossrail tunnel has led to an overall reduction in the noise and vibration levels beneath the studios, due to the operation of the nearby Central line trains of London Underground. This is predominantly due to a reduction of approximately $6 \mathrm{~dB}$ in the 63 $\mathrm{Hz}$ band-limited levels but accompanied by a slight increase, of approximately $2 \mathrm{~dB}$, in the $125 \mathrm{~Hz}$ band. Further analysis indicates that any seasonal variations in vibration levels over the measurement period are negligible, adding weight to the conclusion that the observed changes are a causal effect of the tunnel. The second half of the paper presents results from the model, which aims to simulate the dynamic interaction between the Central line tunnels and those of Crossrail. With nominal parameter values, the results demonstrate qualitative similarities with the measurement findings, thereby adding to the growing body of evidence that dynamic interaction between neighbouring tunnels can be significant.
\end{abstract}

\title{
Keywords
}

Railway vibration, Field measurement, Crossrail, Twin tunnels, Soil-structure interaction

\footnotetext{
${ }^{1}$ Department of Engineering, University of Cambridge, Trumpington Street, Cambridge, CB2 1PZ, UK

${ }^{2}$ Department of Civil and Architectural Engineering, College of Engineering, Qatar University, Doha 2713, Qatar

Corresponding author:

James P Talbot, Department of Engineering, University of Cambridge, Trumpington Street, Cambridge, CB2 1PZ, UK. Email: jpt1000@cam.ac.uk 


\section{Introduction}

In cities around the World, underground railways offer an environmentally-friendly solution to society's increasing demand for mass transport. However, their expansion is leading to a steady growth in the number of locations affected by ground-borne vibration. Due to the inherent roughness of wheels and rails, vibration is generated at the wheel-rail interface that propagates through the ground and up into buildings, where it manifests as perceptible vibration and/or re-radiated noise. The disturbance caused to both occupants and sensitive equipment can be significant, and this is most noticeable in the frequency range from approximately $16 \mathrm{~Hz}$ to 250 $\mathrm{Hz}^{1-3}$.

The growing need to address this problem has driven the development of a number of numerical models to help predict levels of ground-borne vibration ${ }^{4-8}$. Such models not only provide insight into the problem, but also lend themselves as scoping tools for assessing existing, as well as future, railway lines. However, in any model, the complexity of the underground environment necessitates the adoption of various simplifying assumptions, and it is only recently that the significance of these has started to become clear. Commonly disregarded aspects of the underground railway environment include a second (twin) tunnel, piled foundations, discontinuous track-slabs, soil inhomogeneity, inclined soil layers, irregular tunnel-soil contact, and source-building interaction. Recent studies suggest that each of these simplifying assumptions can result in vibration predictions that vary from the simplified cases by at least $5 \mathrm{~dB}$, and potentially up to $20 \mathrm{~dB}^{9-12}$.

This paper considers further one of these simplifying assumptions, namely, the omission of additional tunnels. The importance of studying twin tunnels, with two independent but identical tunnels aligned side-by-side, is clear from the fact that they are a feature of most underground railways. In a rather unique situation, ground-borne vibration from nearby underground railways was measured in the Grand Central Recording Studios (GCRS), in London, during the construction of the Crossrail twin-tunnels. GCRS is a studio facility specialising in audio postproduction for commercials and film trailers. It houses several of its studios in the basement of the building and relies on sound isolation techniques to produce world-class recordings. The construction of the Crossrail tunnels beneath the GCRS building was therefore an immediate concern for the owners, who undertook to record vibration levels in the basement of the building during the construction period. This included a period following the completion of the first tunnel but prior to the commencement of the second, as well as following the completion of both. The resulting data therefore provides an opportunity to analyse differences in the GCRS basement vibration levels with just one Crossrail tunnel present and with both. 
In the first half of the paper, the measured data is analysed to investigate how the construction of the Crossrail tunnels has affected the vibration levels in the GCRS basement. It begins with a brief description of Crossrail, the GCRS site and its location relative to London Underground, before outlining the measurement and analysis procedures. Following the presentation of the results, the second half of the paper presents a boundary-element model, which simulates the dynamic interaction between the new and existing railway tunnels to predict changes in the free-surface vibration levels. These numerical predictions aim to simulate the measurement observations, as well as emphasising the importance of considering twin tunnels in prediction models.

\section{Crossrail and the GCRS Building}

Crossrail is a brand new underground railway connecting the east and west of London via 42 $\mathrm{km}$ of tunnels and 10 new stations ${ }^{13}$. Tunnelling commenced in May 2012, when the first tunnel boring machine, Phyllis, began its journey from Royal Oak to Farringdon. With services due to commence in 2018, Crossrail will provide significantly increased rail capacity in Central London.

The construction of the first (eastbound) Crossrail tunnel passed beneath GCRS on the $16^{\text {th }}$ May 2013; the second (westbound) tunnel followed on the $10^{\text {th }}$ July 2013, passing directly beneath the GCRS building. The two $6.2 \mathrm{~m}$ diameter tunnels sit $16 \mathrm{~m}$ apart, centre-to-centre, and approximately $25 \mathrm{~m}$ beneath GCRS in London Clay. The approximate layering of the ground beneath GCRS comprises $2.5 \mathrm{~m}$ of made ground, $5 \mathrm{~m}$ of river terrace gravel (containing the water table) and approximately $25 \mathrm{~m}$ of London Clay.

The GCRS building is an eight-storey concrete building, including a lower ground floor/basement level, constructed in the late 1970s or early 1980s. It does not have piled foundations, being founded on shallow pad and strip foundations that extend through the made ground onto the terrace gravel. The building is located close to several of the railway lines of London Underground. The detailed tube map shown in Figure 1 indicates that the Central, Bakerloo, Victoria and Northern lines are all likely to contribute to the vibration within the GCRS building.

Further details are unavailable but a schematic diagram, presented later in the paper in Figure 13, summarises the approximate arrangement. 


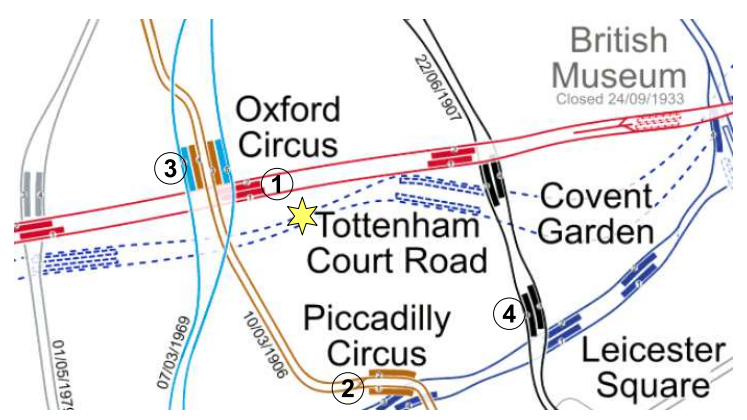

Figure 1. Detailed tube map showing the approximate location of the GCRS building (starred), which lies south of the Central line tunnels (1) and immediately above those of Crossrail (dashed lines) ${ }^{14}$.

\section{Measurement work}

Vibration levels in the GCRS basement were recorded by the studio owners throughout the Crossrail construction period. These measurements were designed with the particular needs of the studio in mind, and the resulting data has a number of limitations from a research perspective. However, with careful analysis, these may be accommodated and some valuable insights gained. The following sections outline the measurement procedure, and how passing trains are characterised in the subsequent analysis, before presenting the results.

\section{Data acquisition}

To assist with train identification, initial measurements were made over a 54-hour period during one weekend. This allowed equipment in the studios to be shut down, thereby reducing the amount of background noise, and minimising the effects of secondary vibration sources. A variety of instrumentation was used to record 27 separate channels of sound and vibration data in different parts of the building. Focus was eventually directed to vibration data measured at the bottom of a disused lift shaft, approximately $4 \mathrm{~m}$ below ground level. This was selected due to the proximity of the measurement location to the underground railways, and its likely sensitivity to changes in the underground environment.

Vertical vibration of the concrete slab at the bottom of the shaft was measured using a Wilcoxcon 731A high-sensitivity accelerometer. This was stud-mounted onto a mounting plate comprising two aluminium discs bonded together using double-sided adhesive tape, thereby providing constrained-layer damping to the discs. The plate was mounted on the concrete slab using glazing putty, and the entire assembly covered with a $25 \mathrm{~cm}$ deep layer of sand within an 
(a)

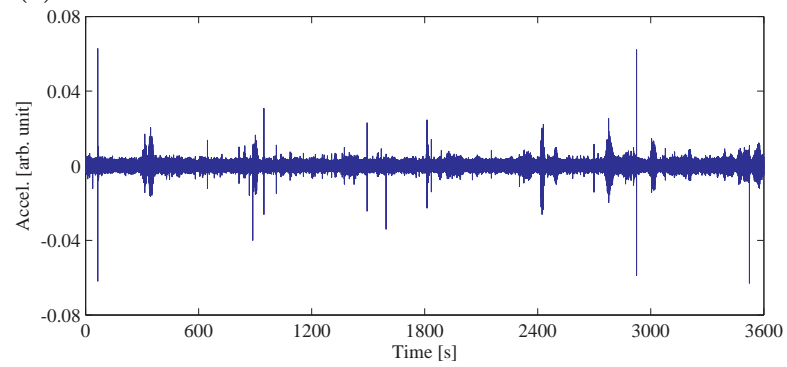

(b)

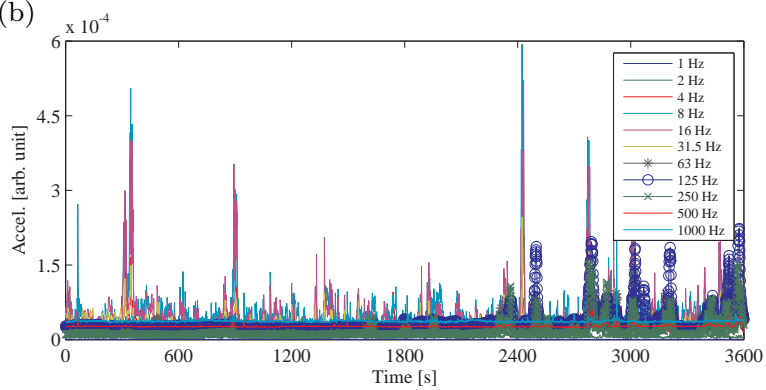

Figure 2. Typical ground-borne vibration time-histories for the period from 5 am to 6 am on a Saturday morning, showing the (a) raw data and (b) octave-band limited data up to $1 \mathrm{kHz}$. For illustration only; linear scales.

enclosure containing sound-absorbing mineral fibre, to prevent acoustic energy coupling into the accelerometer.

The data was recorded using a SINUS Soundbook - a 4-channel portable data-acquisition system. A sampling frequency of $44 \mathrm{kHz}$ was used but the data was subsequently down-sampled to $3.2 \mathrm{kHz}$ for analysis. Both octave and one-third octave band spectra were calculated over a frequency range from $1 \mathrm{~Hz}$ to $1 \mathrm{kHz}$, based on one second intervals. An example set of one-hour vibration time-histories is given in Figure 2, which illustrates the raw data and the results of filtering into different octave bands. Note that, although linear scales are used on the y-axes in Figures 2 to 6 , the units used are noted as arbitrary due to the absence of a calibration factor at the time of measurement. Nevertheless, the data enable ready identification of passing trains, due to their characteristic signatures, whilst the raw data provide aural confirmation and help with identifying the length and magnitude of the pass-by signals. 


\section{Train characterisation and initial observations}

The first step in the analysis was to eliminate the data contaminated by vibration from construction trains running in the newly constructed tunnels. This was made possible by referring to records provided by Crossrail, which gave the times of these trains passing beneath the studios.

It is clear from Figure 1 that a number of Underground lines are likely to contribute to ground-borne vibration in the GCRS building. The train characterisation process was therefore essential for identifying trains from different lines, those running in different directions, passing simultaneously and with unusually high levels of vibration. Being closest to the GCRS building, attention was focussed on the Central line trains, in particular, those running at the beginning (05:48 eastbound from Oxford Circus) and end (00:33 westbound from Tottenham Court) of the day, as indicated by the London Underground timetable. At these times, there is likely to be less overlap between the vibration signals from different trains, making them easier to identify.

Figure 3 presents some raw and $125 \mathrm{~Hz}$ octave-band limited data from the first and last hours of the day, which begin at 05:07 and 00:07 respectively. The first train of the day is clearly evident in the octave band signal as the first of a series of peaks at around 2500 seconds into the time-history (Figure 3(c)). Similarly, the octave band signal from the last hour of data reveals clearly the train pass-bys, with the the last train of the day clear as the last of the peaks at around 1550 seconds (Figure 3(d)).

The $125 \mathrm{~Hz}$ signal is not always the dominant component: the $8 \mathrm{~Hz}$ and $16 \mathrm{~Hz}$ signals can dominate occasionally but this includes times when trains are not running. The peaks in the 125 $\mathrm{Hz}$ signal, however, are found to be the most strongly associated with the trains, corresponding well with the scheduled running times indicated by the London Underground timetable. This sensitivity of the $125 \mathrm{~Hz}$ band to train pass-bys reflects the peak in the train source spectrum, which typically lies in either the $63 \mathrm{~Hz}$ or $125 \mathrm{~Hz}$ octave bands ${ }^{2 ; 15}$.

It is possible to further characterise the Central line trains by their direction of travel, by referring to the timetabled times for each direction. Figure 4 presents example time-histories that focus on a single pass-by in each direction. It is seen that the eastbound signal is characterised by a main peak in the $125 \mathrm{~Hz}$ signal, preceded and succeeded by smaller peaks in the $63 \mathrm{~Hz}$ and $250 \mathrm{~Hz}$ signals respectively. In contrast, the westbound signal contains a gradual rise in level before the main peak of the $125 \mathrm{~Hz}$ signal. In general, it is also observed that the eastbound pass-by is longer in duration. This is because the rate of acceleration of the eastbound trains at this location is lower than the rate of deceleration of the westbound trains. The relative strength of the $63 \mathrm{~Hz}$ signal in the westbound pass-bys may be due to braking or the generally slower 
(a)

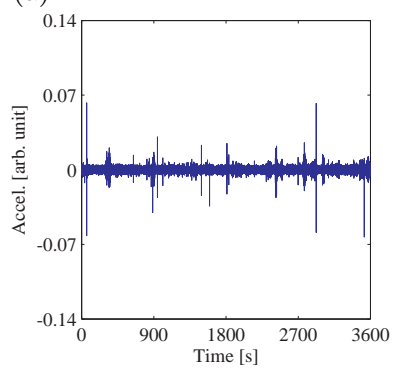

(c)

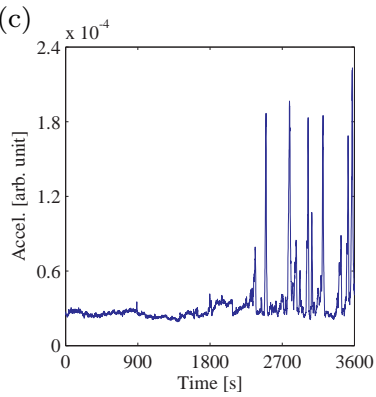

(b)

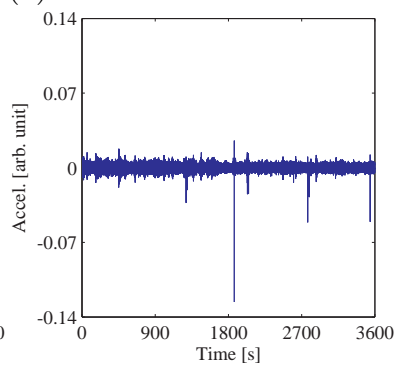

(d)

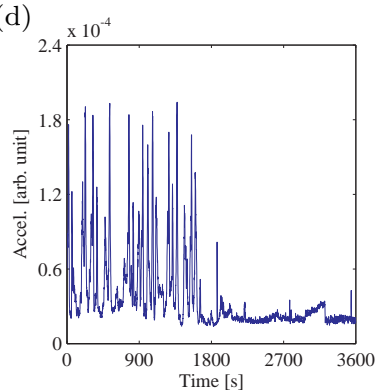

Figure 3. Ground-borne vibration time-histories for the $(a, c)$ first eastbound and $(b, d)$ last westbound Central line trains: (a,b) raw data; (c,d) $125 \mathrm{~Hz}$ octave-band limited data.

speed of these trains, or perhaps due to a wave scattering effect, since the westbound tunnel is closer to the GCRS building than the eastbound tunnel (see Figure 13).

The data has also revealed occurrences of trains passing each other in the eastbound and westbound tunnels, and of trains generating unusually high vibration levels, perhaps due to increased levels of wheel roughness. One of these occurrences is shown in Figure 5 (a,c), in which a signal from one of the more distant lines appears at around 1600 seconds, followed by a westbound and eastbound Central line train at approximately 1650 seconds and 1670 seconds. An example of what may be a westbound train with excessive wheel roughness is shown in Figure 5(b,d). This exhibits significantly higher vibration levels in both the $63 \mathrm{~Hz}$ and $125 \mathrm{~Hz}$ bands than those evident in Figure 4.

Following a similar method of train characterisation, train signatures can be obtained for the inbound and outbound directions of the Bakerloo, Victoria and Northern lines. Figure 6 shows five different train pass-bys occurring at approximately 560, 580, 650, 760 and 790 seconds. By referring to the timetable and focussing on the dominant $125 \mathrm{~Hz}$ signal, these pass-bys are 
(a)

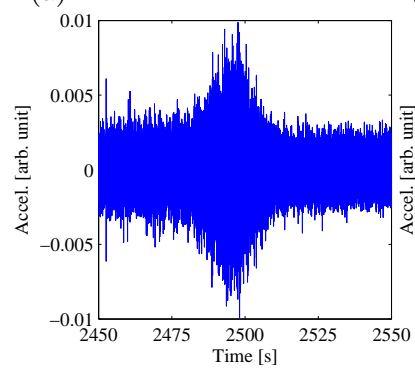

(c)

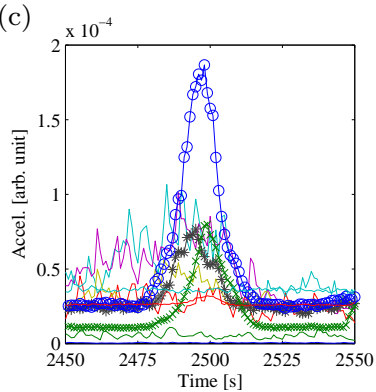

(b)

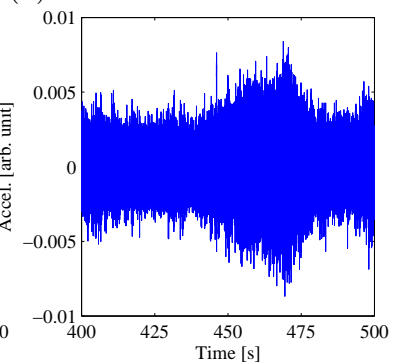

(d)

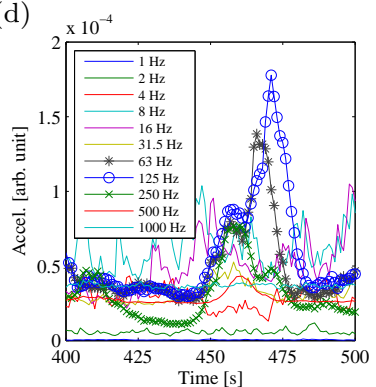

Figure 4. Typical ground-borne vibration time-histories for the $(a, c)$ eastbound and $(b, d)$ westbound Central line trains: $(a, b)$ raw data; $(c, d)$ octave-band limited data up to $1 \mathrm{kHz}$.

identified as Victoria line northbound, Bakerloo line southbound, Central line eastbound, one of the Northern line directions and Central line westbound respectively. The dominance of the closer Central line is clear.

\section{Measurement results}

With knowledge of typical Central line train signals, the analysis focusses on the differences in vibration levels observed with just one (in June 2013) and then two (in July 2013) of the new Crossrail tunnels present. Figure 7 shows the octave-band limited vibration levels for a 30-minute period, approximately four weeks before and two weeks after constructing the second tunnel. The eastbound and westbound Central line train signatures are clearly evident in both sets of data. However, after the construction of the second tunnel (Figure 7(a)), there are clearly a number of peaks in the $63 \mathrm{~Hz}$ signal that have reduced in magnitude, whilst some of those in the $125 \mathrm{~Hz}$ signal have increased. 
(a)

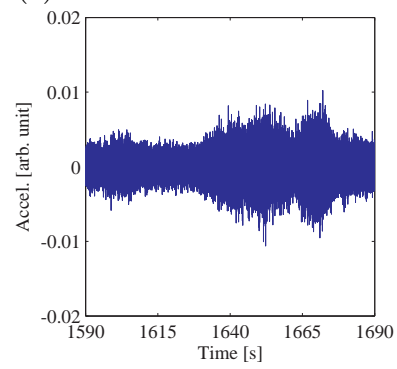

(c)

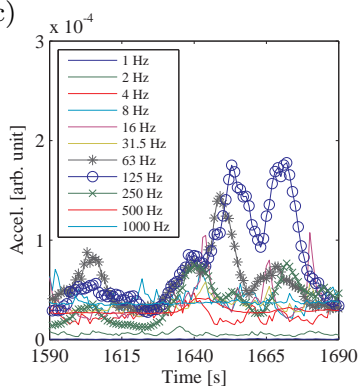

(b)

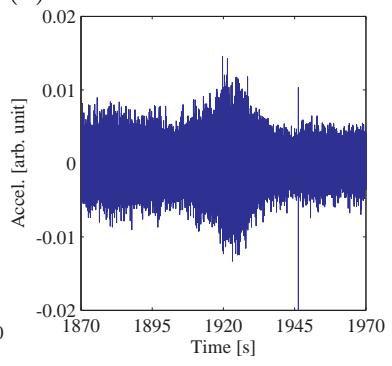

(d)

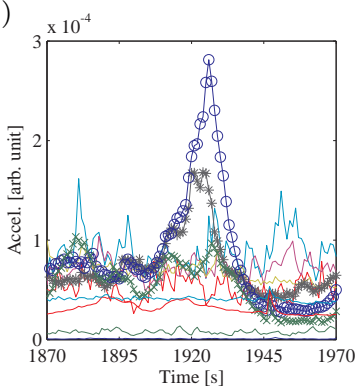

Figure 5. Examples of unusual ground-borne vibration time-histories from Central line trains, showing $(a, c)$ trains passing each other and $(b, d)$ a train generating unusually high vibration levels: $(a, b)$ raw data; $(c, d)$ octave-band limited data up to $1 \mathrm{kHz}$.

This may be observed better in Figure 8, which compares typical westbound and eastbound Central line signals measured during single train pass-bys before and after the construction of the second tunnel. The westbound signals (Figure 8(a)) exhibit very similar levels in the 125 $\mathrm{Hz}$ and $250 \mathrm{~Hz}$ bands before and after the tunnel construction, but the $63 \mathrm{~Hz}$ level has reduced significantly. Ignoring what is believed to be a separate event at around 80 seconds, the 31.5 $\mathrm{Hz}$ band signal also exhibits a noticeable change. In contrast, the eastbound data (Figure 8(b)) shows negligible changes in the $31.5 \mathrm{~Hz}, 63 \mathrm{~Hz}$ and $250 \mathrm{~Hz}$ band levels as a result of the second tunnel, but a slight increase in the $125 \mathrm{~Hz}$ band level.

The results presented in Figures 7 and 8 represent only a limited data set. The observed changes in the $63 \mathrm{~Hz}$ and $125 \mathrm{~Hz}$ band peak levels may be further investigated by considering a more extensive set from three separate periods covering different stages of the Crossrail construction. Each period covers the majority of an operating day for the Central line: on 09/06/13 and 06/07/2013, before the construction of the second tunnel (which passed beneath GCRS on 

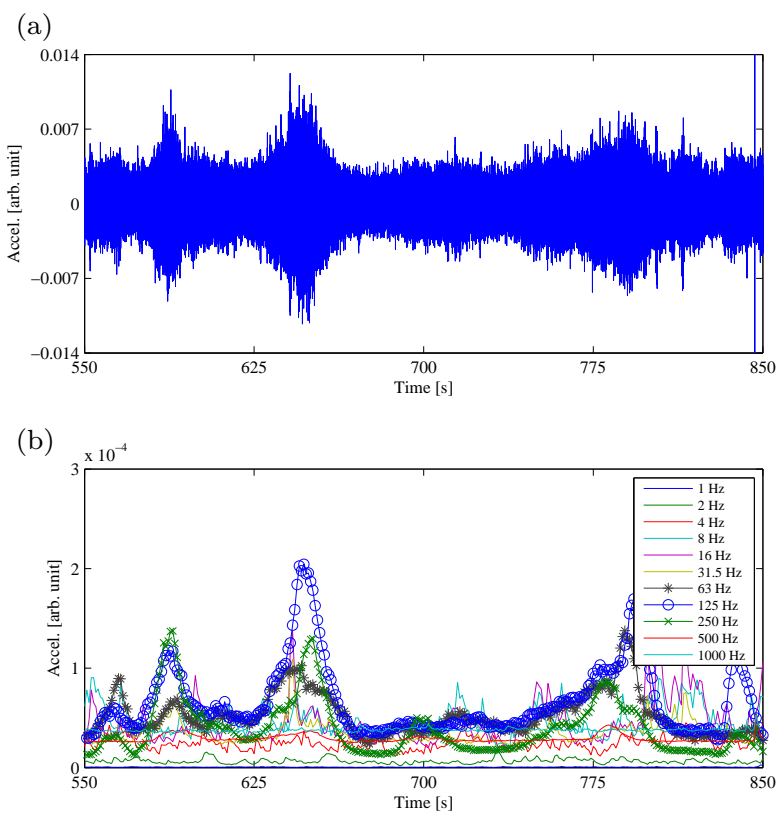

Figure 6. Example ground-borne vibration time-history comprising signatures from multiple Underground lines: (a) raw data and (b) octave-band limited data up to $1 \mathrm{kHz}$.

10/07/2013); and on 23/07/2016, after its construction. The peak levels from these octave bands are plotted as histograms in Figure 9. Note that, in this data, the $63 \mathrm{~Hz}$ band levels are due solely to westbound trains, whereas the $125 \mathrm{~Hz}$ band levels are due to trains travelling in both directions. It is clear that the peak levels in the $63 \mathrm{~Hz}$ signal are consistently greater in magnitude for the two dates prior to the tunnel construction. For the $125 \mathrm{~Hz}$ signal, the presence of data from both east and westbound trains produces a bimodal distribution of peaks. However, a change is also evident in this band, with peak levels tending to be slightly lower prior to the tunnel construction, consistent with the earlier observations.

These observations suggest that the construction of the second tunnel has indeed coincided with noticeable changes in the vibration environment beneath GCRS. However, this in itself does not prove a causal effect: the changes could equally be due to seasonal variations, such as might be expected from changes in the water table, for example.

To investigate potential seasonal variations, a further data set is considered, which provides one year's worth of vibration data from the GCRS basement. Figure 10 shows the weekly variation in 
(a)

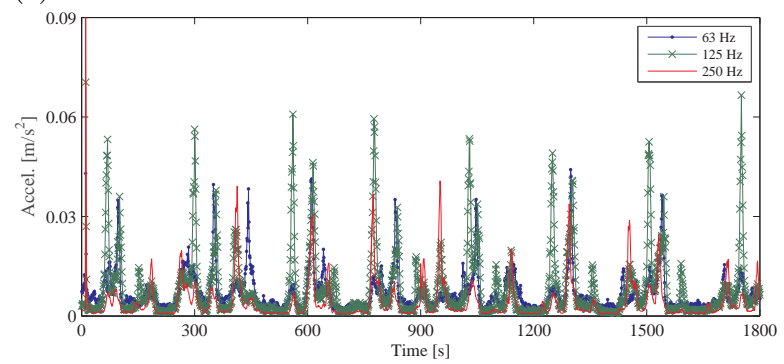

(b)

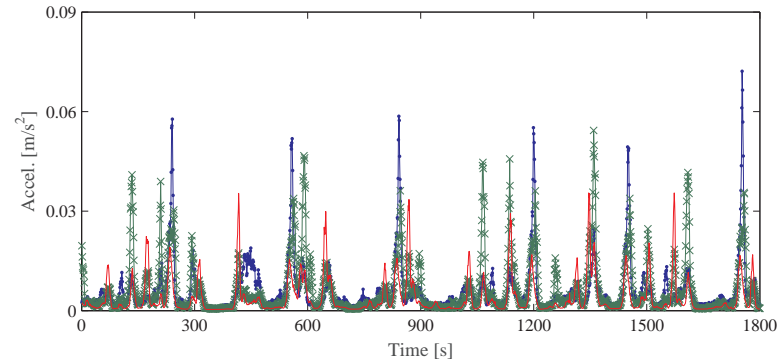

Figure 7. Octave-band limited vibration levels due to Central line train operation during a 30-minute period (a) after and (b) before the construction of the second Crossrail tunnel.

the $63 \mathrm{~Hz}$ and $125 \mathrm{~Hz}$ band-limited peak vibration levels extracted from the same hour's worth of data each week. The variation is plotted along with the modal peak levels from the histogram data of Figure 9. In this data, it is clear that the drop in the $63 \mathrm{~Hz}$ band levels occurred after the construction of the second tunnel, and that subsequent levels remain reasonably steady. This suggests that (a) the reduction, which is approximately $6 \mathrm{~dB}$, is indeed due to the construction of the second tunnel, and (b) that any seasonal variations over the measurement period are negligible. The change in the $125 \mathrm{~Hz}$ signal is less evident but the data does suggest a slight increase in vibration levels, of approximately $2 \mathrm{~dB}$, due to the second tunnel, and, again, that any seasonal variations in this case are negligible.

A small amount of audio data was collected independently by the studio owners in January 2007, at the same basement location within the GCRS building as the later vibration measurements. This was achieved using a B\&K instrumentation microphone, mounted on a standard recording stand using a vibration decoupling clamp, and with the cable arranged so as to minimise low-frequency mechanical transmission to the microphone. 

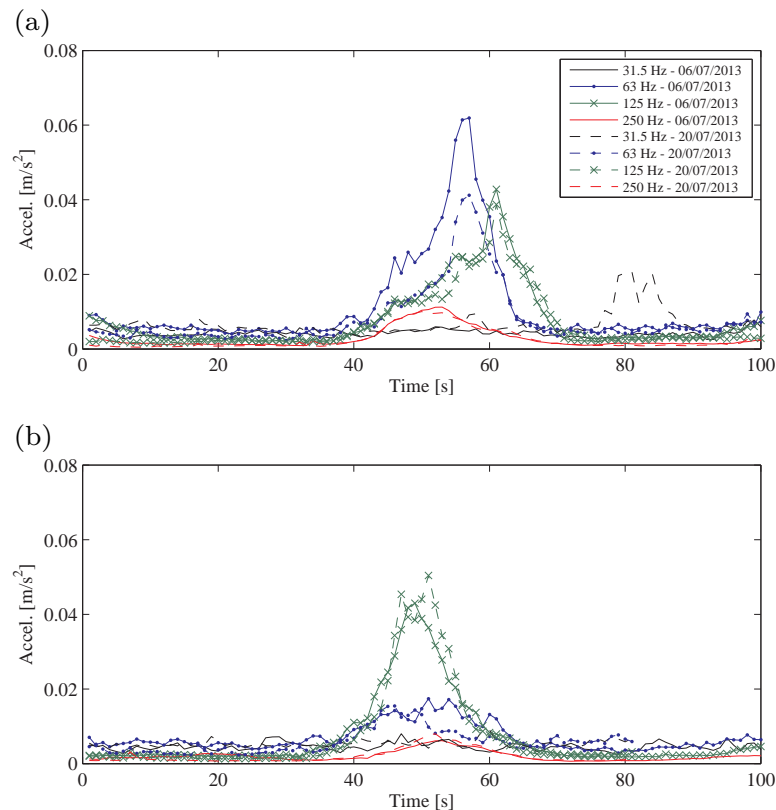

Figure 8. Comparison of octave-band limited vibration levels from (a) westbound and (b) eastbound Central line trains operating before and after the construction of the second Crossrail tunnel.

This audio data enables a comparison of re-radiated noise levels before and after the construction of the Crossrail tunnels. Figure 11 shows the $63 \mathrm{~Hz}$ and $125 \mathrm{~Hz}$ band-limited noise levels prior to Crossrail, and those following the construction of both tunnels. It is clear that, whereas the $125 \mathrm{~Hz}$ band levels have changed only slightly, the $63 \mathrm{~Hz}$ band levels have dropped by approximately $5 \mathrm{~dB}$. Although there are likely to be other factors influencing the noise and vibration environment over a 7-year period, these results also lend support to the conclusion that the Crossrail tunnels have significantly affected the vibration environment beneath GCRS.

In summary, the measurement data presented in this section provides evidence for a dynamic interaction effect between the new twin-tunnels of Crossrail and the existing ground-borne vibration environment. In particular, they indicate that, overall, the construction of a second tunnel can reduce the vibration experienced at a particular receiver. In this case, the reduction is observed predominantly in the $63 \mathrm{~Hz}$ octave band. Based on typical properties for London Clay (see Table 1), the $44 \mathrm{~Hz}$ and $88 \mathrm{~Hz}$ limiting frequencies of this band correspond to shear wavelengths in the ground ranging from $5 \mathrm{~m}$ to $2.5 \mathrm{~m}$, that is, of the same order as the 6.2 
(a)

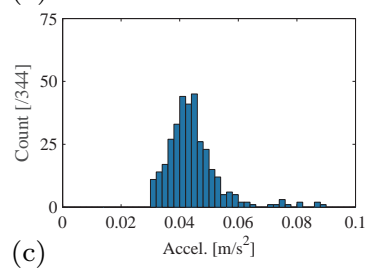

(c)

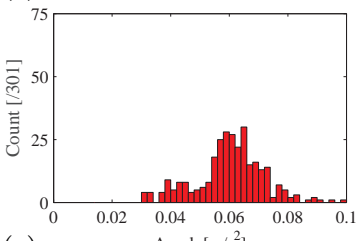

(e)

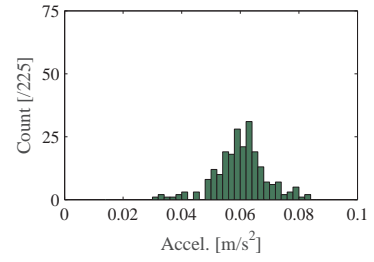

(b)

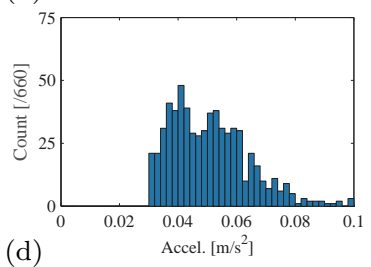

(d)

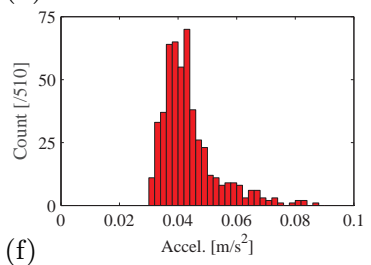

(f)

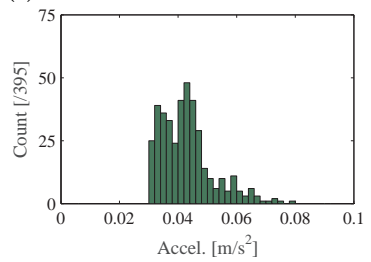

Figure 9. Histograms of peak vibration levels measured in the (a,c,e) $63 \mathrm{~Hz}$ and (b,d,f) $125 \mathrm{~Hz}$ octave bands, from Central line trains operating $(a, b)$ approximately two weeks after, $(c, d)$ four days before and $(e, f)$ four weeks before the construction of the second Crossrail tunnel.

m diameter of the tunnel. A possible explanation for the reduced vibration levels is therefore scattering of the incident waves by the newly installed tunnel.

Such findings are in line with theoretical studies, which have found the interaction between neighbouring underground railway tunnels to be significant, resulting in changes in vibration levels of up to $20 \mathrm{~dB}$ depending on the frequency, tunnel geometry and orientation ${ }^{9}$. In the following section, a numerical model is presented that aims to simulate the measurement observations by capturing the essential dynamic characteristics of the particular tunnel layout beneath GCRS.

\section{Modelling work}

The aim of the current numerical study is to establish if theoretical evidence may be found that supports the findings of the measurement work undertaken to date. The model comprises four 

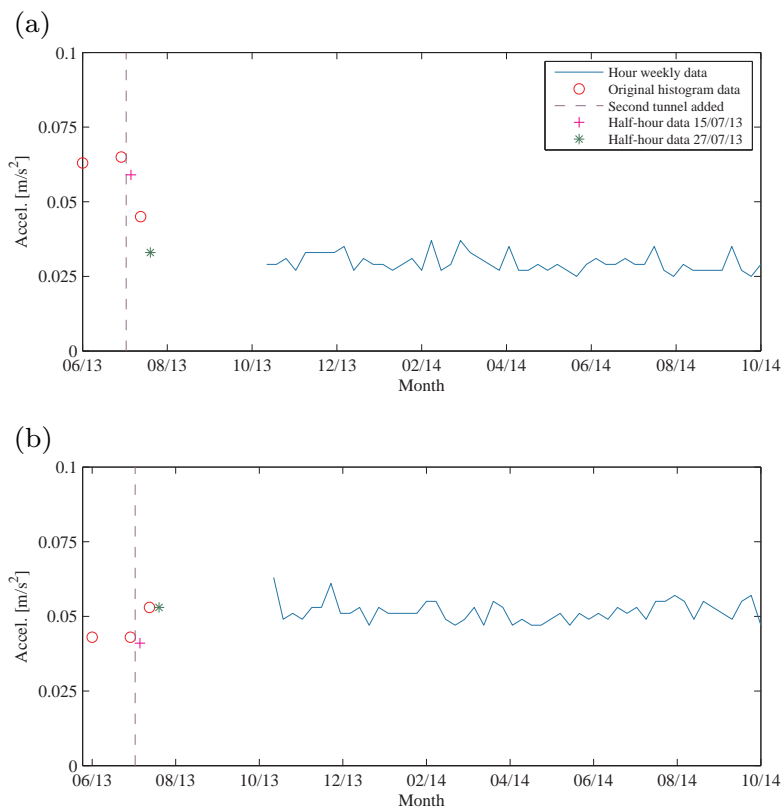

Figure 10. Weekly variation in the (a) $63 \mathrm{~Hz}$ and (b) $125 \mathrm{~Hz}$ band-limited peak vibration levels following the construction of the second Crossrail tunnel, together with modal peak levels measured immediately before and after the construction.

neighbouring railway tunnels, representing the Central line and Crossrail tunnels, embedded in a homogeneous half-space. For computational efficiency, the tunnels are assumed to be straight and parallel, and no other neighbouring structures are modelled explicitly. The overall geometry is representative but only nominal material properties are assumed. Nevertheless, the model accounts for the essential dynamic behaviour of the main components of the tunnel-soil system. By observing changes in the free-surface vibration levels, the model is expected to provide at least a qualitative indication of how vibration levels are affected by tunnel interactions, as well their sensitivity to changes in the relative positions of the tunnels.

The assumption of parallel, longitudinally invariant tunnels enables the use of a 2.5D modelling approach. In this approach, which is adopted in the majority of existing studies ${ }^{4-8}$, the calculations are performed in the wavenumber domain $\left(\xi_{y}\right)$, thereby representing the full $3 \mathrm{D}$ response of the system and the radiated wavefield on a $2 \mathrm{D}$ mesh. The response in the space 
(a)

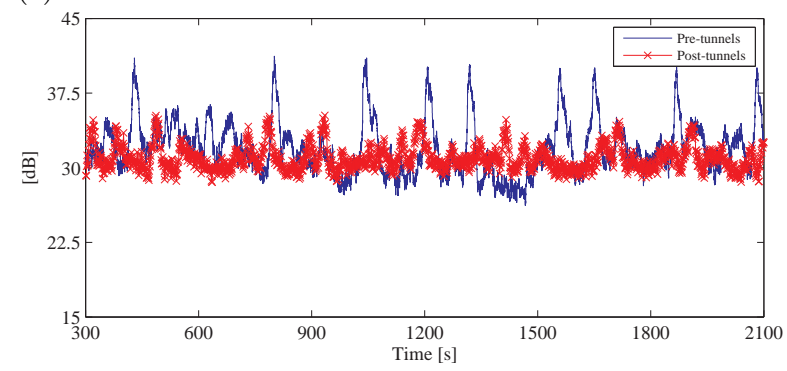

(b)

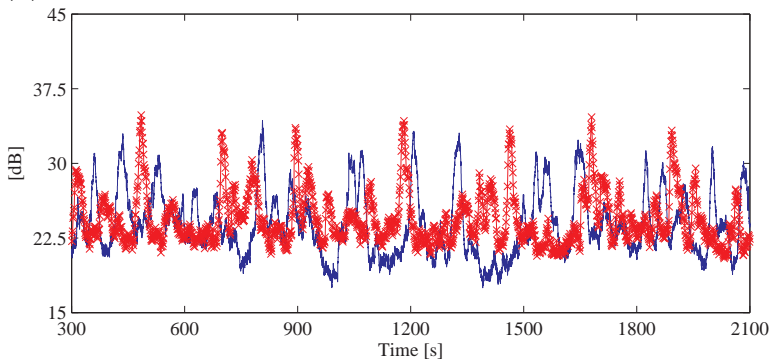

Figure 11. Comparison of (a) $63 \mathrm{~Hz}$ and (b) $125 \mathrm{~Hz}$ band-limited re-radiated noise levels before (January 2007) and after (September 2013) the construction of the Crossrail tunnels.

domain $(u(y, \omega))$ is obtained by applying the inverse Fourier transform as:

$$
u(y, \omega)=\frac{1}{2 \pi} \int_{-\infty}^{\infty} \tilde{u}(\xi, \omega) e^{\left(i \xi_{y} y\right)} d \xi_{y}
$$

where $\tilde{u}\left(\xi_{y}, \omega\right)$ is the response in the wavenumber domain. The following sections summarise the modelling of the soil, tunnel and railway track, as well as presenting the final results. Full details of the methodology may be found in the references provided.

\section{Soil modelling}

In order to model the dynamic soil-structure interaction appropriately, it is necessary to include an acceptable representation of the soil. In common with other studies, given the low strain amplitudes associated with ground-borne vibration, the soil is assumed to behave in a linearelastic manner, and the soil domain is modelled using the boundary-element (BE) method ${ }^{16}$. This 
is a particularly suitable method because wave radiations are inherently accounted for, thereby avoiding spurious reflections from artificial boundaries and yielding accurate solutions within the interior domain. The method used here employs the Green's functions for a homogeneous half-space, which are calculated with the aid of the ElastoDynamics Toolbox (EDT) using the direct stiffness and thin-layer methods of modelling wave propagation in layered media ${ }^{17}$.

The derivation of $2.5 \mathrm{D}$ boundary integral equations has been presented previously by Sheng et al., ${ }^{4}$ based on the $2.5 \mathrm{D}$ reciprocal theorem, and by François et al. ${ }^{18}$ based on the 3D integral representation. The current method adopts the latter approach, including the regularization procedure used to avoid singular integration at the source points. The BE mesh consists of a total of $N_{s}$ constant node-collocated elements, over which tractions and displacements are assumed to be uniform. For each of the $N_{s}$ nodes of the BE mesh, the displacements and tractions are related by

$$
[\tilde{\mathbf{H}}+\mathbf{I}] \tilde{\mathbf{u}}=\tilde{\mathbf{G}} \tilde{\mathbf{p}}
$$

where $\tilde{\mathbf{H}}$ and $\tilde{\mathbf{G}}$ are the $3 N_{s} \times 3 N_{s}$ BE system matrices describing the behaviour of the soil in terms of its Young's modulus $(E)$, density $(\rho)$, Poisson's ratio $(\nu)$, damping loss factor $(\eta)$ and the frequency of interest $(f)$. The tilde symbol denotes that the calculations are performed in the wavenumber-frequency domain. The $3 N_{s} \times 1$ vectors $\tilde{\mathbf{u}}$ and $\tilde{\mathbf{p}}$ are assembled from the complex displacement and traction amplitudes of each node as

$$
\begin{aligned}
& \tilde{\mathbf{u}}=\left\{\begin{array}{lllllllll}
\tilde{u}_{x}^{1} & \tilde{u}_{y}^{1} & \tilde{u}_{z}^{1} & \tilde{u}_{x}^{2} & \tilde{u}_{y}^{2} & \tilde{u}_{z}^{2} \cdots \tilde{u}_{x}^{N_{s}} & \tilde{u}_{y}^{N_{s}} & \tilde{u}_{z}^{N_{s}}
\end{array}\right\}^{\top}
\end{aligned}
$$

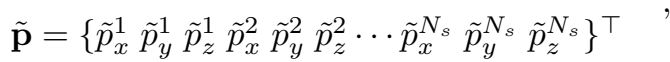

where $\tilde{u}^{j}$ and $\tilde{p}^{j}$ are the displacement and traction vectors of node $j$. The identity matrix $\mathbf{I}$ represents the integral-free term in the case of an unbounded domain, which is the case for an embedded cavity.

Equation (2) is rearranged as

$$
\begin{aligned}
\tilde{\mathbf{u}} & =[\tilde{\mathbf{H}}+\mathbf{I}]^{-1} \tilde{\mathbf{G}} \tilde{\mathbf{p}} \\
\tilde{\mathbf{u}} & =\tilde{\mathbf{H}}_{s} \tilde{\mathbf{p}}
\end{aligned}
$$

in which $\tilde{\mathbf{H}}_{s}$ is the frequency response function (FRF) matrix relating displacements and tractions at the frequency of interest. The BE system matrices $\tilde{\mathbf{H}}$ and $\tilde{\mathbf{G}}$ are assembled according to the routine described by Domìnguez. ${ }^{16}$ 
Once the solution at the boundary is known from equation (4), the radiated wavefield $\left(\tilde{\mathbf{u}}_{r w}\right)$ at any point in the domain may be computed by

$$
\tilde{\mathbf{u}}_{r w}=\tilde{\mathbf{G}} \tilde{\mathbf{p}}-\tilde{\mathbf{H}} \tilde{\mathbf{u}} .
$$

To ensure convergence of the solution, throughout the analysis, a minimum of six elements are used per wavelength, in accordance with the recommendations of Domìnguez. ${ }^{16}$

\section{Tunnel modelling}

The tunnel model is identical to that developed by Forrest and Hunt ${ }^{6}$. Each tunnel is represented by cylindrical thin-shell theory, in which the equations of motion are again formulated in the wavenumber-frequency domain. The axi-symmetry of the tunnel cross-section enables any applied force to be represented by a Fourier series. Furthermore, if the applied loading comprises traction components that are harmonic in space and time, the equations of motion are satisfied by similarly harmonic displacement components. Thus, the modal displacements $\left\{\tilde{U}_{y n}, \tilde{U}_{\theta n}, \tilde{U}_{r n}\right\}^{\top}$ at the mean radius $a$ of the tunnel due to applied forces in the longitudinal, tangential and radial directions $\left\{\tilde{Q}_{y n}, \tilde{Q}_{\theta n}, \tilde{Q}_{r n}\right\}^{\top}$ are given by

$$
\left\{\begin{array}{l}
\tilde{U}_{y n} \\
\tilde{U}_{\theta n} \\
\tilde{U}_{r n}
\end{array}\right\}=\frac{-a\left(1-\nu^{2}\right)}{E_{t} h_{t}} \tilde{\mathbf{A}}^{-1}\left\{\begin{array}{l}
\tilde{Q}_{y n} \\
\tilde{Q}_{\theta n} \\
\tilde{Q}_{r n}
\end{array}\right\},
$$

where $h$ is the tunnel wall thickness, and $E_{t}$ and $\nu_{t}$ are the Young's modulus and Poisson's ratio respectively. For symmetric loading, the tangential component is associated with $\sin n \theta$, and the longitudinal and radial components are associated with $\cos n \theta$, and vice versa for antisymmetric loading. The elements of matrix $\tilde{\mathbf{A}}$ for the symmetric and antisymmetric cases are given by Forrest and Hunt ${ }^{19}$ and Hussein and $\mathrm{Hunt}^{7}$ respectively.

Given the particular track model used here (and described later), the tunnel invert is subject to a point harmonic load. It is necessary to decompose this into its space-harmonic components before finding the corresponding tunnel displacements. Forrest and Hunt ${ }^{6}$ present the procedure for casting a point load in a form that can be applied in the thin-shell formulation. The spatial variation around the shell circumference is represented by the discrete ring modes, while the variation of the load is represented by $\frac{\delta(\theta)}{a}$. This part can be written as a linear combination of 
the ring modes by means of a Fourier series on the interval $-\pi<\theta \leq \pi$ :

$$
\frac{\delta(\theta)}{a}=\frac{1}{2 \pi a}+\sum_{n=1}^{\infty} \frac{1}{\pi a} \cos n \theta=\sum_{n=0}^{\infty} b_{n} \cos n \theta,
$$

where $\delta(\theta)$ is the Dirac delta function.

Using the representation of the point load in equation (7), the input force can be written in a form that suits the formulation in equation (6), in order to calculate the responses due to symmetric and antisymmetric forces for a given ring mode. The FRF matrix of the tunnel is formulated using the dynamic stiffness approach by dividing the shell into $N_{t}$ nodes. Each node has three degrees-of-freedom (DoF), representing the longitudinal, tangential and radial directions. The responses due to symmetric and antisymmetric loading are summed for all ring modes and used to assemble a FRF matrix $\left(\tilde{\mathbf{H}}_{t}\right)$ relating the response at each DoF to the applied force.

\section{Coupling procedure}

The adoption of node-collocated elements in the BE mesh facilitates the coupling of the tunnel walls to the soil cavities. This requires the number of elements in each tunnel $\left(N_{t}\right)$ to be equal to those in the BE meshes $\left(N_{s}\right)$. Before coupling, two transformations are required. Firstly, the soil FRF matrix is modified to relate displacements and forces (rather than tractions) at each node. This is achieved simply by dividing the FRF matrix by the area of the (identical) elements used. Secondly, the tunnel FRF matrix is modified to relate displacements and forces in Cartesian coordinates, rather than in cylindrical coordinates. This is performed after arranging the elements of the FRF matrix in the tangential, longitudinal and radial order to conform with the coordinate system of the soil model after transformation. The transformed FRF matrix reads:

$$
\tilde{\mathbf{H}}_{t}^{c}=\mathbf{T}_{r}^{\top} \tilde{\mathbf{H}}_{t} \mathbf{T}_{r}
$$

where the transformation matrix $\left(\mathbf{T}_{r}\right)$ is a matrix of size $3 N_{t} \times 3 N_{t}$ given by

$$
\mathbf{T}_{r}=\left[\begin{array}{llll}
\mathbf{t}_{1} & & & \\
& \mathbf{t}_{2} & & \\
& & \ddots & \\
& & & \mathbf{t}_{N_{t}}
\end{array}\right]
$$


For each node, the elements of the transformation sub-matrices are given by

$$
\mathbf{t}_{i}=\left[\begin{array}{ccc}
\cos \theta_{i} & 0 & -\sin \theta_{i} \\
0 & 1 & 0 \\
-\sin \theta_{i} & 0 & -\cos \theta_{i}
\end{array}\right]
$$

These transformations enable the tunnel walls and soil cavities to be coupled directly in the wavenumber domain, by applying the principles of compatibility of displacements $\left(\left(\tilde{\mathbf{U}}_{t}\right)=\left(\tilde{\mathbf{U}}_{s}\right)\right)$ and equilibrium of forces. At each soil-tunnel interface:

$$
\begin{aligned}
\tilde{\mathbf{U}}_{s} & =\tilde{\mathbf{H}}_{s} \tilde{\mathbf{f}}_{s} \\
\tilde{\mathbf{U}}_{t} & =\tilde{\mathbf{H}}_{t}^{c}\left(\tilde{\mathbf{f}}_{a}-\tilde{\mathbf{f}}_{s}\right) \\
\tilde{\mathbf{f}}_{s} & =\left(\tilde{\mathbf{H}}_{s}+\tilde{\mathbf{H}}_{t}^{c}\right)^{-1} \tilde{\mathbf{H}}_{t}^{c} \tilde{\mathbf{f}}_{a},
\end{aligned}
$$

in which $\tilde{\mathbf{f}}_{a}$ is the force applied to the tunnel, and $\tilde{\mathbf{f}}_{s}$ is the resulting force applied to the soil. Knowing $\tilde{\mathbf{f}}_{s}$, the radiated wavefield at any point in the soil can be calculated using equation (5).

\section{Track modelling}

The procedure followed by Forrest and Hunt ${ }^{6}$ to couple a railway track to an embedded tunnel (tunnel-in-soil) is adopted here. An infinitely long track model is used, comprising a slab beam supporting a rail beam (representing both rails), and with axle masses at constant spacings to represent the unsprung mass of the train. See Figure 12. Both the slab and rail beams are modelled as Euler-Bernoulli beams, and the slab beam is coupled to the tunnel invert via distributed springs to represent continuous resilient support. The source excitation is generated by introducing a rail roughness displacement $\left(\delta=\Delta e^{i \omega t}\right)$ between the axle masses and the rail, based on Frederich's empirical rail-roughness spectrum ${ }^{20}$ :

$$
S_{\delta}(\omega)=\frac{1}{v} \frac{a_{\delta}}{\left(b_{\delta}+\frac{\omega}{2 \pi v}\right)^{3}}
$$

in which $v$ is the train speed (assumed here to be $40 \mathrm{~km} / \mathrm{hr}$ ), $a_{\delta}$ is the unevenness and $b_{\delta}$ is the waviness.

Before adding any axle masses, the slab and rail beams are coupled to the embedded tunnels in the wavenumber-frequency domain. Coupling is achieved through the interaction forces acting between the slab and rail beams, and between the tunnel and slab beam. Once the driving point FRFs, due a harmonic point load, of the uncoupled rail beam, slab beam and tunnel invert are 


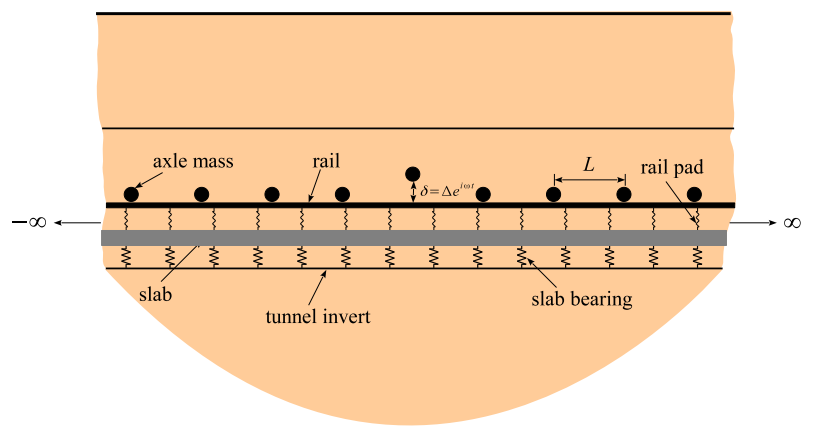

Figure 12. The tunnel model comprising: an infinitely long track-slab, continuously supported on resilient bearings along the tunnel invert; a rail beam, continuously supported on resilient railpads; and constantly spaced masses representing the unsprung mass of the train. Excitation is provided by a roughness displacement $\delta$.

known, the responses of the various components of the coupled system can be computed. The resulting response at any point in the soil is calculated by multiplying the transfer function from equation (5) by the force on the tunnel invert due a point harmonic load on the rail beam.

The responses of the rail beam and the soil must be transformed to the space domain in order to add axle masses. Using the spatial shifting concept presented by Forrest and Hunt ${ }^{6}$, the rail responses at the positions of the axle masses are first computed and formed into a FRF matrix form. The axle masses $\left(m_{a}\right)$ are then added to the model as inertia terms of the form $-m_{a} \omega^{2} u$, where $u$ is the displacement at the axle's position. This is done for the diagonal elements of the rail beam dynamic stiffness matrix, except for that in the centre position, to which an axle mass with an imposed roughness displacement $\left(\delta=\Delta e^{i \omega t}\right)$ is added. From this modified dynamic stiffness matrix, the vector of displacements at the axle positions is computed and used to calculate the corresponding interaction forces acting on the rail beam.

The interaction forces are used together with the soil FRF matrix, which is assembled from the soil responses using the shifting concept, to calculate the soil transfer functions due to the addition of the axle masses. Random vibration theory ${ }^{21}$ is finally employed to calculate the power spectral density (PSD) of the soil response, by first summing the squares of the soil transfer functions and then weighting the summation by the rail irregularity PSD given in equation (12).

\section{Modelling results}

Four neighbouring railway tunnels are modelled explicitly: one pair to represent the twin tunnels of the Central line, the other to represent Crossrail. See Figure 13. The tunnels are 


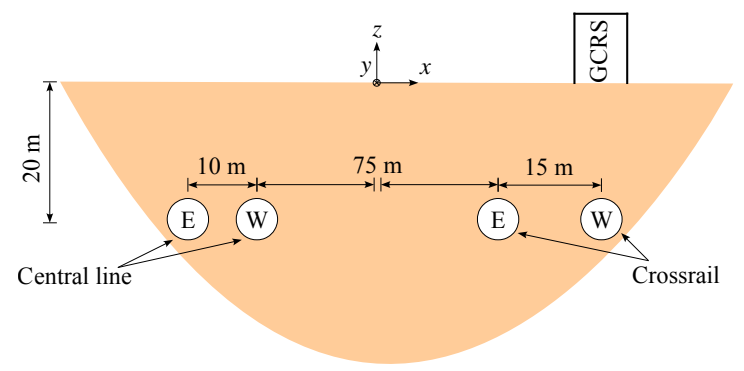

Figure 13. Schematic diagram of the modelled railway tunnels. The location of the GCRS building lies above the westbound Crossrail tunnel, at a distance of $100 \mathrm{~m}$ from the eastbound Central line tunnel.

assumed to be made of concrete, and embedded at a depth of $20 \mathrm{~m}$ in London Clay. Each tunnel has a circular cross-section of $6 \mathrm{~m}$ diameter and $0.25 \mathrm{~m}$ wall thickness. The Central line tunnels are separated by $10 \mathrm{~m}$, while the Crossrail tunnels are separated by $15 \mathrm{~m}$. The GCRS building is located on top of the westbound Crossrail tunnel, at a distance of $100 \mathrm{~m}$ from the eastbound tunnel of the Central line. Note that the spacings between the tunnels are approximate, and that the GCRS building is not modelled explicitly.

The soil and tunnel parameters used in the model are listed in Table 1. These are broadly representative of bored tunnels in London Clay ${ }^{15}$. The parameters used for the track models are taken from Forrest and Hunt ${ }^{6}$, and summarised in Table 2. These are nominal values, assumed to be the same for both lines, and do not represent specifically the particular track systems employed. In both cases, axle masses of $500 \mathrm{~kg}$ are spaced equally at $20 \mathrm{~m}$ intervals along the rails to represent the unsprung mass of the trains.

Table 1. Soil and tunnel parameters used in the modelling work.

\begin{tabular}{lll}
\hline Parameter & Soil & Tunnel \\
\hline Young's modulus $(E)$ & $286 \mathrm{MPa}$ & $20 \mathrm{GPa}$ \\
Density $(\rho)$ & $1980 \mathrm{~kg} / \mathrm{m}^{3}$ & $2500 \mathrm{~kg} / \mathrm{m}^{3}$ \\
Poisson's ratio $(\nu)$ & 0.49 & 0.15 \\
Damping loss factor $(\eta)$ & 0.04 & 0.03 \\
Shear wave speed $\left(c_{s}\right)$ & $220 \mathrm{~m} / \mathrm{s}$ & $1860 \mathrm{~m} / \mathrm{s}$ \\
Pressure wave speed $\left(c_{p}\right)$ & $1570 \mathrm{~m} / \mathrm{s}$ & $2910 \mathrm{~m} / \mathrm{s}$ \\
\hline
\end{tabular}

In order to investigate the effect of adding a neighbouring tunnel on the free-surface vibration levels, two scenarios of three tunnels (the Central line tunnels and a single Crossrail tunnel) are compared to the four-tunnel scenario illustrated in Figure 13, in which the second Crossrail 
Table 2. Rail and slab beam parameters used in the modelling of the railway tracks.

\begin{tabular}{lll}
\hline Parameter & Rail & Slab \\
\hline Bending stiffness $(E I)$ & $10 \mathrm{MPa} \cdot \mathrm{m}^{4}$ & $1430 \mathrm{MPa} \cdot \mathrm{m}^{4}$ \\
Mass per unit length $(m)$ & $100 \mathrm{~kg} / \mathrm{m}$ & $3500 \mathrm{~kg} / \mathrm{m}$ \\
Railpad stiffness $\left(k_{r p}\right)$ & $400 \mathrm{MPa}$ & - \\
Slab bearing stiffness $\left(k_{s b}\right)$ & - & $1262 \mathrm{MPa}$ \\
Damping loss factor $(\eta)$ & 0.15 & 0.25 \\
\hline
\end{tabular}

tunnel is assumed to have been constructed. In the first scenario, the second Crossrail tunnel is assumed to be the westbound tunnel; in the second, it is assumed to be the eastbound tunnel. In both scenarios, the vibration field is assumed to be generated by just one of the Central line tunnels, and the vibration levels in the transverse, longitudinal and vertical directions are calculated at two receiver points on the free-surface $\left(\mathrm{pt}_{1}\right.$ and $\mathrm{pt}_{2}$ ), located directly above the Crossrail tunnels. Thus, a total of four modelling cases are considered, as summarised in Table 3. The simulations are run for 11 frequencies in the range from $16 \mathrm{~Hz}$ to $160 \mathrm{~Hz}$, corresponding to the third-octave band centre frequencies.

Figure 14 shows the acceleration PSDs predicted for Case 1, in the transverse, longitudinal and vertical directions, before and after adding the westbound Crossrail tunnel. The vibration field is generated by the eastbound Central line tunnel. It can be seen that the addition of the Crossrail tunnel changes the PSD levels, and that the change is more pronounced at the second receiver point $\left(\mathrm{pt}_{2}\right)$, which is the approximate location of the GCRS building. In the frequency bands below $63 \mathrm{~Hz}$, the changes in the longitudinal and vertical vibration levels are negligible, whereas the transverse levels are increased on average by approximately $5 \mathrm{~dB}$. In the frequency bands at and above $63 \mathrm{~Hz}$, the additional tunnel results in increased levels in all three directions. For the vertical acceleration PSD at $\mathrm{pt}_{2}$, the changes are confined to the frequency bands between 50 $\mathrm{Hz}$ and $100 \mathrm{~Hz}$, with an average increase of approximately $8 \mathrm{~dB}$.

The predicted acceleration PSDs for Case 2 are presented in Figure 15. In this case, the westbound Central line tunnel generates the vibration field, representing a scenario in which the incident wavefield to the Crossrail tunnels is not reflected/diffracted by the intermediate structure of the eastbound Central line. At the first receiver point ( $\left.\mathrm{pt}_{1}\right)$, the vibration levels in all three directions remain essentially unchanged by the additional tunnel, except for an increase in the transverse direction of approximately $6 \mathrm{~dB}$ in the $40 \mathrm{~Hz}$ band. However, at $\mathrm{pt}_{2}$, all levels are predicted to change above $32 \mathrm{~Hz}$. The levels in the vertical direction increase by approximately $6 \mathrm{~dB}$ in the $63 \mathrm{~Hz}$ and $80 \mathrm{~Hz}$ bands. 
Table 3. Cases considered in the modelling work.

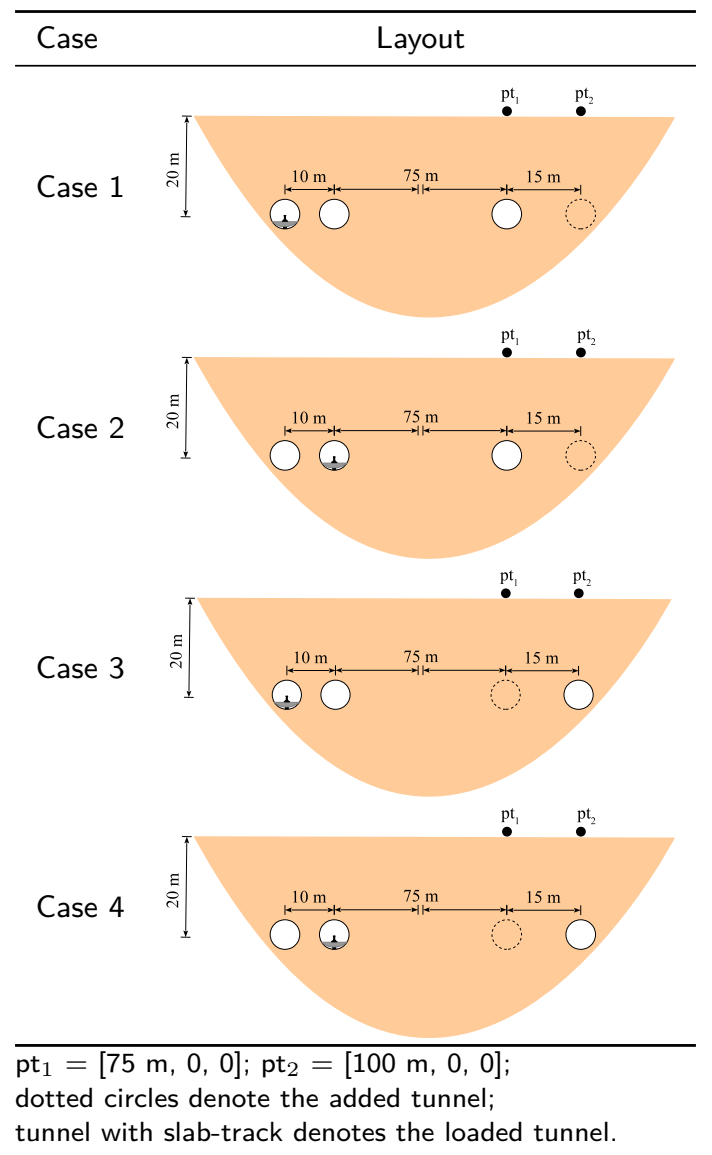

Figures 16 and 17 present the results for Cases 3 and 4, when the additional Crossrail tunnel is assumed to be the eastbound one. Figure 16 corresponds to Case 3, where the vibration field is generated by the eastbound Central line tunnel. There are clear changes to all the acceleration PSDs, in all three directions and at both $\mathrm{pt}_{1}$ and $\mathrm{pt}_{2}$, due to the addition of the Crossrail tunnel. The dominant change in this case is an increase in the longitudinal response of approximately $12 \mathrm{~dB}$ at $50 \mathrm{~Hz}$. In the vertical direction, the response at $63 \mathrm{~Hz}$ increases by approximately 7 $\mathrm{dB}$ for $\mathrm{pt}_{1}$, but remains unchanged for $\mathrm{pt}_{2}$, while at frequencies below $48 \mathrm{~Hz}$ a similar change at both receiver points is observed. In the transverse direction, the effect of the additional tunnel is more apparent at the second receiver point.

Figure 17 corresponds to Case 4, where the vibration field is now generated by the westbound Central line. In this case, the dominant effect of the additional tunnel is an increased response at 
(a)

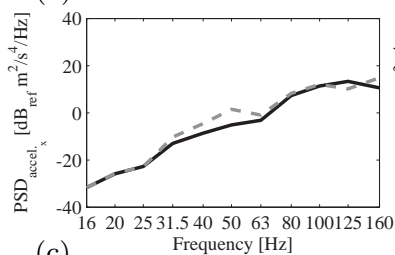

(c)

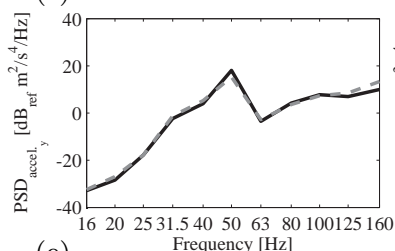

(e)

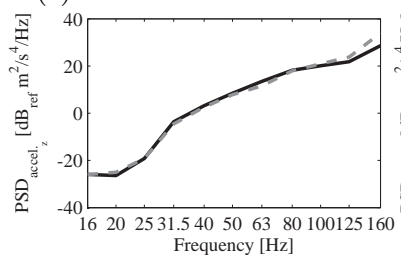

(b)

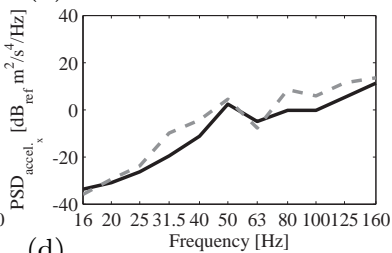

(d)

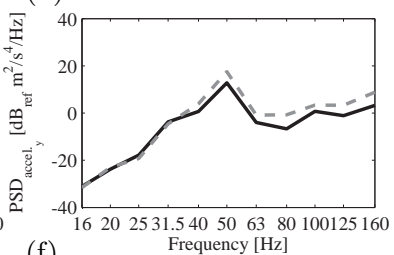

(f)

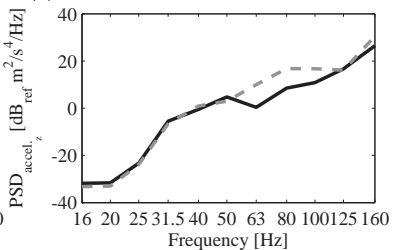

Figure 14. Acceleration PSD for Case 1 in the $(a, b)$ transverse, $(c, d)$ longitudinal and $(e, f)$ vertical directions, for the three-tunnel system (solid line) and the four-tunnel system (dashed line). Responses are calculated at $(\mathrm{a}, \mathrm{c}, \mathrm{e}) \mathrm{pt}_{1}=[75 \mathrm{~m}, 0,0]$ and at $(\mathrm{b}, \mathrm{d}, \mathrm{f}) \mathrm{pt}_{2}=[100 \mathrm{~m}, 0,0]$.

frequencies between $31.5 \mathrm{~Hz}$ and $50 \mathrm{~Hz}$. It is also interesting to observe that the vertical response at $\mathrm{pt}_{2}$ drops for frequencies between $63 \mathrm{~Hz}$ and $100 \mathrm{~Hz}$ - the only significant reduction in levels predicted by the model for the two locations considered.

The results presented in this section reinforce previous predictions that dynamic interaction exists between neighbouring tunnels, and that this can have a significant influence on the vibration levels at local receivers. As with the measurement results presented earlier, these results indicate that changes are localised within certain frequency bands, depending most likely on the vibration wavelengths present and the diameter and spacing of the tunnels. However, although the changes predicted here are broadly similar in magnitude to those indicated by the measurements, the predictions are predominantly of increased, rather than reduced, vibration levels. 
(a)

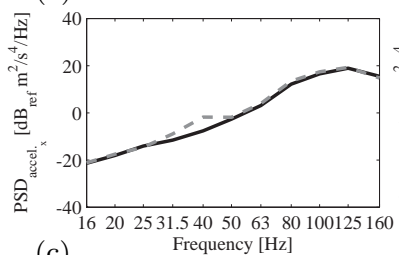

(c)

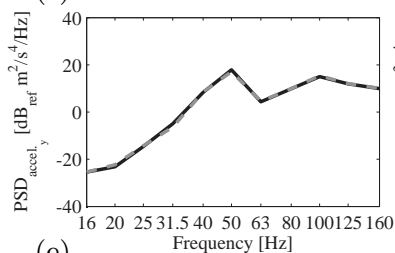

(e)

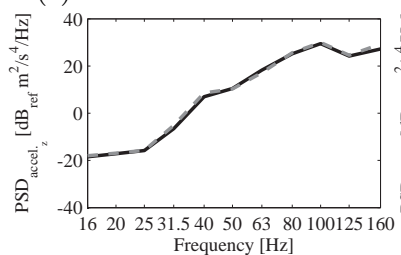

(b)

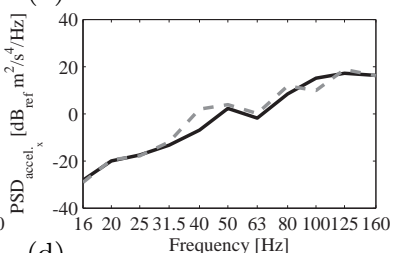

(d)

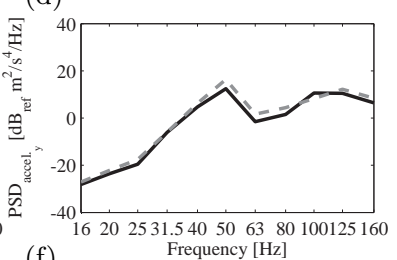

(f)

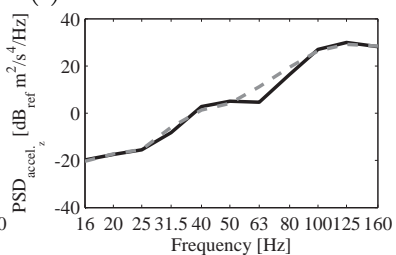

Figure 15. Acceleration PSD for Case 2 in the $(a, b)$ transverse, $(c, d)$ longitudinal and $(e, f)$ vertical directions, for the three-tunnel system (solid line) and the four-tunnel system (dashed line). Responses are calculated at $(\mathrm{a}, \mathrm{c}, \mathrm{e}) \mathrm{pt}_{1}=[75 \mathrm{~m}, 0,0]$ and at $(\mathrm{b}, \mathrm{d}, \mathrm{f}) \mathrm{pt}_{2}=[100 \mathrm{~m}, 0,0]$.

\section{Conclusions}

The significance of the dynamic interaction between neighbouring underground railway tunnels has been highlighted recently by a few theoretical studies. However, there are no known reports of such interaction being observed in practice. This paper has presented results from both a theoretical boundary-element model and an analysis of measured data from a unique case study, namely, the construction of the new twin-tunnels of Crossrail beneath the Grand Central Recording Studios in central London.

The measurement results provide compelling evidence for a dynamic interaction effect between the new tunnels and the existing ground-borne vibration environment. The measurements indicate that the construction of the second Crossrail tunnel has led to an overall reduction in the vibration levels beneath the studios due to the operation of nearby Central line trains. This is predominantly due to a reduction of approximately $6 \mathrm{~dB}$ in the $63 \mathrm{~Hz}$ band-limited levels 
(a)

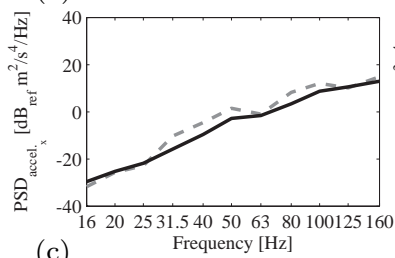

(c)

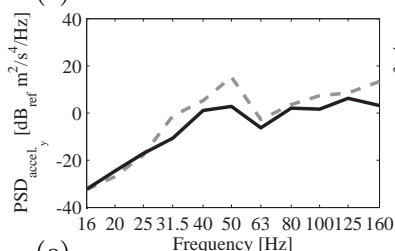

(e)

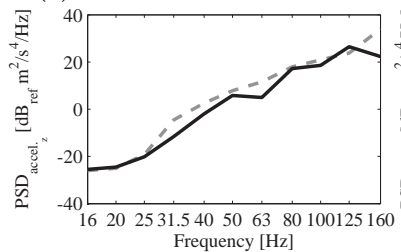

(b)

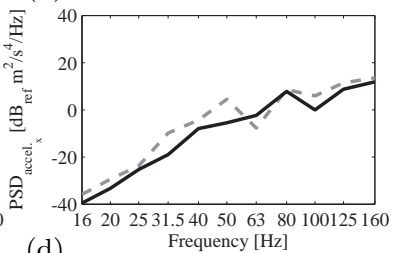

(d)

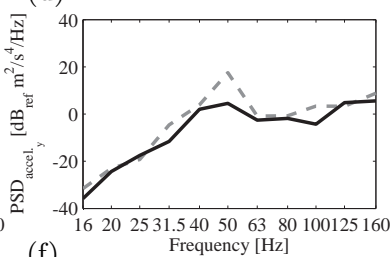

(f)

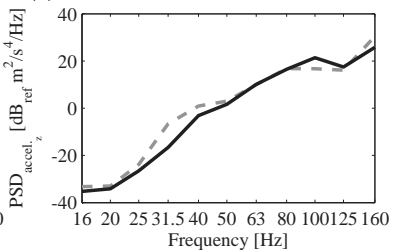

Figure 16. Acceleration PSD of modelling Case 3 in the $(a, b)$ transverse, $(c, d)$ longitudinal and $(e, f)$ vertical directions for a three-tunnel system (solid line) and a four-tunnel system (dashed line). Responses are calculated for $(a, c, e)$ at $\mathrm{pt}_{1}=[75 \mathrm{~m}, 0 \mathrm{~m}, 0 \mathrm{~m}]$ and for $(\mathrm{b}, \mathrm{d}, \mathrm{f})$ at $\mathrm{pt}_{2}=[100 \mathrm{~m}, 0 \mathrm{~m}, 0 \mathrm{~m}]$.

but accompanied by a slight increase, of approximately $2 \mathrm{~dB}$, in the $125 \mathrm{~Hz}$ band. Analysis of a year's worth of data indicates that, in this case, any seasonal variations in vibration levels over the measurement period are negligible, adding weight to the conclusion that the observed changes are a causal effect of the tunnel.

These results are in line with those from the theoretical model, which also predicts significant changes in vibration levels due to the second tunnel and that these changes are localised within certain frequency bands, depending most likely on the vibration wavelengths present and the diameter and spacing of the tunnels. However, although the predicted changes are broadly similar in magnitude to those indicated by the measurements, the predictions are predominantly of increased, rather than reduced, vibration levels. The model is clearly limited in its prediction accuracy, despite aiming to capture the essential dynamic characteristics of the particular tunnel layout. In particular, the omission of other structures lying between the Central line and Crossrail tunnels, the failure to explicitly represent the GCRS building, and the availability of only nominal 
(a)

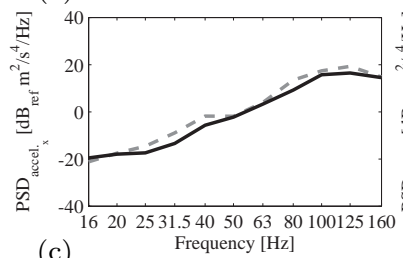

(c)

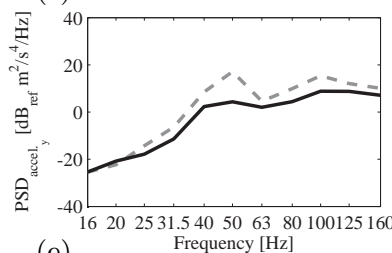

(e)

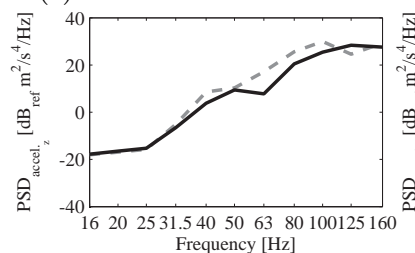

(b)

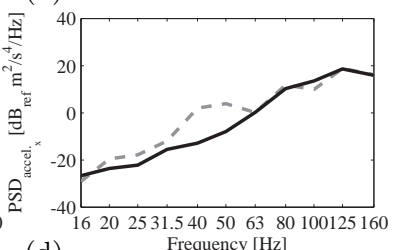

(d)

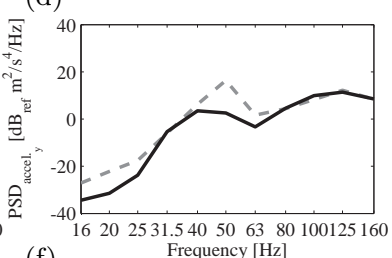

(f)

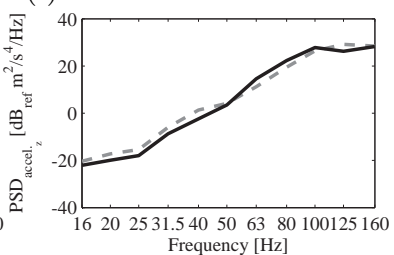

Figure 17. Acceleration PSD of modelling Case 4 in the $(a, b)$ transverse, $(c, d)$ longitudinal and $(e, f)$ vertical directions for a three-tunnel system (solid line) and a four-tunnel system (dashed line). Responses are calculated for $(a, c, e)$ at $\mathrm{pt}_{1}=[75 \mathrm{~m}, 0 \mathrm{~m}, 0 \mathrm{~m}]$ and for $(\mathrm{b}, \mathrm{d}, \mathrm{f})$ at $\mathrm{pt}_{2}=[100 \mathrm{~m}, 0 \mathrm{~m}, 0 \mathrm{~m}]$.

values for the various model parameters, are all likely to influence its accuracy. Nevertheless, the results presented here clearly add to the growing body of evidence that dynamic interaction between neighbouring tunnels can be significant.

\section{Acknowledgements}

The authors wish to thank Mr Ivor Taylor, of the Grand Central Recording Studios, for providing the measurement data and information about Crossrail and ground conditions; and also colleagues in KU Leuven for providing the EDT and BEMFUN toolboxes used in the BE model. 


\section{Funding}

The funding provided by EPSRC (grant reference EP/K006665/1) to conduct the numerical work under the MOTIV project is also acknowledged.

\section{References}

1. Howarth $\mathrm{H}$ and Griffin $\mathrm{M}$. The annoyance caused by simultaneous noise and vibration from railways. Journal of the Acoustical Society of America 1991; 89(5): 2317-2323.

2. Heckl M, Hauck G and Wettschureck R. Structure-borne sound and vibration from rail traffic. Journal of Sound and Vibration 1996; 193: 175-184.

3. Vadillo EG, Herreros J and Walker JG. Subjective reaction to structurally radiated sound from underground railways: field results. Journal of Sound and Vibration 1996; 193: 65-74.

4. Sheng X, Jones CJC and Thompson DJ. Modelling ground vibration from railways using wavenumber finite- and boundary-element methods. Proceedings of the Royal Society A 2005; 461: 2043-2070.

5. Degrande G, Clouteau D, Othman R et al. A numerical model for ground-borne vibrations from underground railway traffic based on a periodic finite element-boundary element formulation. Journal of Sound and Vibration 2006; 293: 645-666.

6. Forrest JA and Hunt HEM. Ground vibration generated by trains in underground tunnels. Journal of Sound and Vibration 2006; 294: 706-736.

7. Hussein MFM and Hunt HEM. A numerical model for calculating vibration from a railway tunnel embedded in a full-space. Journal of Sound and Vibration 2007; 305: 401-431.

8. Hussein MFM, François S, Schevenels M et al. The use of fictitious force method for efficient calculation of vibration from a tunnel embedded in a multi-layered half-space. Journal of Sound and Vibration 2014; 333: 6996-7018.

9. Kuo KA, Hunt HEHM and Hussein MFM. The effect of a twin tunnel on the propagation of ground-borne vibration from an underground railway. Journal of Sound and Vibration 2011; 330: 6203-6222.

10. Jones S, Kuo K, Hussein MFM et al. Prediction uncertainties and inaccuracies resulting form common assumptions in modelling vibration from underground railways. Proceedings of the Institution of Mechanical Engineers Part F: Journal of Rail and Rapid Transit 2012; 226(5): 501512.

11. Lopes $\mathrm{P}$, Costa PA, Calçada $\mathrm{R}$ et al. Influence of soil stiffness on building vibrations due to railway traffic in tunnels: numerical study. Computers $\mathcal{E}$ Geotechnics 2014; 61: 277-291. 
12. Coulier P, Lombaert G and Degrande G. The influence of source-receiver interaction on the numerical prediction of railway induced vibrations. Journal of Sound and Vibration 2014; 333: 2520-2538.

13. Crossrail, 2016. URL http://www. crossrail.co.uk.

14. Detailed London Transport map, 2015. URL http://carto.metro.free.fr/cartes/ metro-tram-london.

15. Degrande G, Schevenels M, Chatterjee P et al. Vibrations due to a test train at variable speeds in a deep bored tunnel embedded in london clay. Journal of Sound and Vibration 2006; 293: 626-644.

16. Domínguez J. Boundary Elements in Dynamics. Computational Mechanics Publications and Elsevier Applied Science, 1993.

17. Schevenels M, François S and Degrande G. EDT: An elastodynamics toolbox for matlab. Computers ES Geosciences 2009; 35(80): 1752-1754.

18. François S, Schevenels M, Lombaert G et al. A 2.5D coupled FE-BE methodology for the dynamic interaction between longitudinally invariant structures and a layered halfspace. Computer Methods in Applied Mechanics and Engineering 2010; 199(23-24): 1536-1548.

19. Forrest JA and Hunt HEM. A three-dimensional tunnel model for calculation of train-induced ground vibration. Journal of Sound and Vibration 2006; 294: 678-705.

20. Frederich F. Die gleislage-aus fathrzeugtechnischer sicht [Effect of tack geometry on vehicle performance]. Zitschrift für Eisenbahnwesen und Vekehrstechnik-Glasers Annalen 1984; 108: 355362.

21. Newland DE. An introduction to random vibrations, spectral and wavelet analysis. Longman, 1993. 